\title{
Multifocal Motor Neuropathy with Persistent Conduction Block: The Seminal Case
}

\author{
François Ochsner ${ }^{\mathrm{a}}$ Laurent Tatu ${ }^{\mathrm{b}}$ \\ ${ }^{a}$ Department of Neurology, CHUV Lausanne, Lausanne, Switzerland; 'bepartment of Anatomy and Department of \\ Neuromuscular diseases, CHRU Besançon, University of Franche-Comté, Besançon, France
}

\section{Keywords}

History of neurology · Peripheral neuropathy · Conduction block

\begin{abstract}
Although multifocal motor neuropathy (MMN) is now recognized as a distinct, albeit rare, neurological condition, the path to its recognition was long and winding. This article provides an insight into the medical history of MMN "patient zero" and the first scientific publication that led to the recognition of MMN by the medical community.

Multifocal motor neuropathy is nowadays recognized as a disease that produces asymmetric muscle weakness and cramping, with spontaneous motor unit activity (fasciculations and myokymia) but without sensory disorder. From an electrophysiological point of view, the neuropathy is characterized by persistent conduction blocks that usually initially affect the proximal upper extremity. The path to recognizing this rare entity was long and winding. In this article, we describe the first known patient suffering from this disease and the scientific context of its emergence, leading to the first publication on the subject, written by Gérard Roth (19232006) and his colleagues at the Neurology Department of Geneva University Hospital (Switzerland) [Eur Neurol. 1986;25(6):416-23].

(c) 2020 S. Karger AG, Basel
\end{abstract}

\section{Patient Zero}

A man born in 1930 had suffered from cramps in his right hand since 1969. In 1974, he began to complain of a right hand weakness. The patient was examined in the Neurology Department of Geneva University Hospital in 1977, by which time he was suffering from paralysis of his right hand and leg. Electroneuromyographic examination revealed proximal motor conduction blocks. The etiological assessment did not reveal any abnormalities or history of hereditary disease. In 1979, the patient's condition had worsened, but the electrophysiological status was unchanged, with the same conduction blocks. The last examination took place in 1984 , at which time the patient had become tetraplegic, but still had not experienced any sensory disturbances. Motor conduction blocks were present in every nerve studied in the upper and lower limbs (Fig. 1). The patient died 3 years later.

\section{The Birth of Multifocal Motor Neuropathy with Persistent Conduction Block}

Conduction blocks had been known since the 19th century, but the notion of neurapraxia with transient block was not specified until 1942, when Seddon (1903- karger@karger.com www.karger.com/ene

(c) 2020 S. Karger AG, Base

Karger!
Laurent Tatu

Department of Anatomy and Department of Neuromuscular diseases CHRU Besançon, University of Franche-Comté

3 Boulevard Fleming, FR-25030 Besançon Cedex (France)

laurent.tatu@univ-fcomte.fr 
1977) wrote on the subject in his work on the classification of nerve injuries [2]. Two years later, DennyBrown (1901-1981) and Brenner (1913-2008) established a clear relationship between focal demyelination

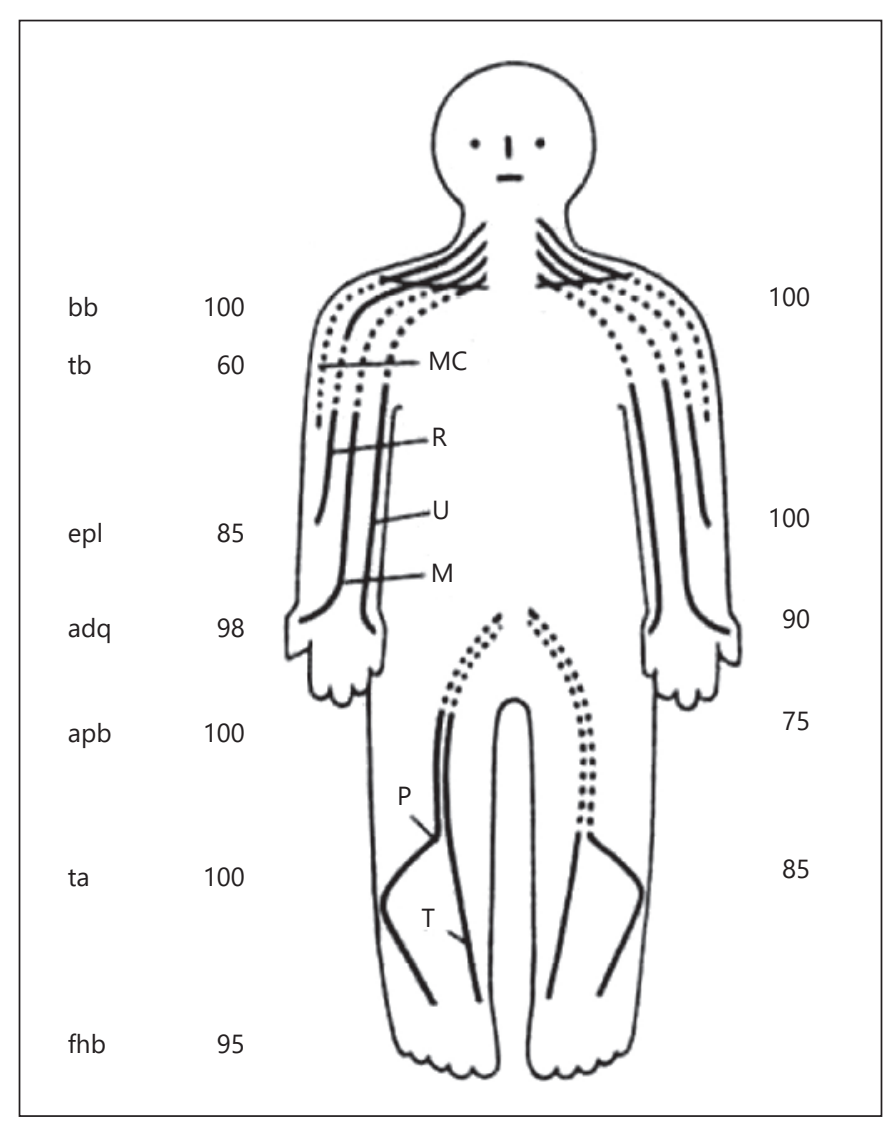

Fig. 1. Distribution of the conduction blocks in patient zero [1]. and conduction block [3]. This relationship was definitively proven by the experimental work of McDonald (1933-2006) in 1963 [4]. In 1978, Gérard Roth published the first report of persistent conduction blocks (lasting more than 2 years), which he had observed in a patient suffering from a hereditary disease that caused the peripheral nerves to be susceptible to compression [5].

During the American Academy of Neurology meeting in April 1979, Richard A. Lewis, Austin J Sumner, Mark J Brown, and Arthur K Asbury presented a poster titled "Chronic multifocal demyelinative neuropathy: A unique disorder with persistent conduction block." Five patients had developed sensory motor symptoms with persistent conduction block outside of the usual entrapment sites [6]. They published this first series of asymmetric demyelinating sensory motor neuropathy with persistent conduction block in September 1982 [7].

In 1984, Gérard Roth, Josette Rohr, and François Ochsner submitted their manuscript entitled "Motor neuropathy with proximal multifocal persistent conduction block" to the Journal of Neurological Sciences. It described patient zero and a second patient with the same electro-clinical features. Unfortunately, the manuscript was rejected by the editor, who believed that the authors were inexperienced and that the patients suffered from amyotrophic lateral sclerosis. The manuscript was then modified to describe only the first case. The paper "Motor neuropathy with proximal multifocal persistent conduction block, fasciculations and myokima, evolution to tetraplegia," now including Michel Magistris as an author, was submitted to European Neurology in June 1985 and finally published in June 1986 (Fig. 2) [1].

\title{
Motor Neuropathy with Proximal Multifocal Persistent Conduction Block, Fasciculations and Myokymia
}

\author{
Evolution to Tetraplegia \\ G. Rotha, J. Rohrb, M.R. Magistrisc, F. Ochsnera \\ alectromyographic Unit. Department of Physical Medicine and Rehabilitation: "Neurological Clinic; and \\ "Division of Clinical Neurophysiology. Iniversity Hospital. (ieneva. Swit/erland
}

Fig. 2. Seminal article published in 1986 [1]. 
At a meeting of the American Association of Electromyography and Electrodiagnosis in October 1985, Gareth J Parry and Stephen Clarke presented two patients with "Pure motor neuropathy with multifocal conduction block masquerading as Motor Neuron Disease"[8]. Parry and Clarke went on to publish reports of five similar cases in 1988 [9].

The concept of pure motor neuropathy with multifocal conduction block, a rare chronic immune-mediated neuropathy, was definitively accepted as a nosographic entity at the end of the 1980s. The subsequent years were marked by the improvement of electrophysiological techniques, the development of peripheral nerve MRI and specific anti-ganglioside antibodies, and the emergence of intravenous immunoglobulins, an efficient therapy.

\section{Acknowledgement}

The authors would like to thank Jennifer Dobson for proofreading the article.

\section{Conflict of Interest Statement}

The authors declare no competing interests.

\section{Funding Sources}

The authors did not receive any funding.

\section{Author Contributions}

The 2 authors contributed equally to the study. Francois Ochsner and Laurent Tatu: design, data analysis and interpretation, literature search, and writing of the manuscript.

\section{References}

1 Roth G, Rohr J, Magistris MR, Ochsner F. Motor neuropathy with proximal multifocal persistent conduction block, fasciculations and myokymia. Evolution to tetraplegia. Eur Neurol. 1986;25(6):416-23.

2 Seddon HJ. A classification of nerve injuries. Br Med J. 1942;2(4260):237-9.

3 Denny-Brown D, Brenner C. The effect of percussion of nerve. J Neurol Neurosurg Psychiatry. 1944;7(3-4):76-95.
4 McDonald WI. The effects of experimental demyelination on conduction in peripheral nerve: a histological and electrophysiological study. II. Electrophysiological observations. Brain. 1963;86:501-24.

5 Roth G. Intranervous regeneration of lower motor neuron -1 . Study of 1,153 motor axon reflexes. Electromyogr Clin Neurophysiol. 1978;18(3-4):(I)225-88-(II)311-50.

6 Lewis RA, Sumner AJ, Brown MJ, Asbury AK. Chronic multifocal demyelinative neuropathy: a unique disorder with persistent conduction block. Neurology. 1979;29(4):610-1.
7 Lewis RA, Sumner AJ, Brown MJ, Asbury AK. Multifocal demyelinating neuropathy with persistent conduction block. Neurology. 1982;32(9):958-64.

8 Parry GJ, Clarke S. Pure motor neuropathy with multifocal conduction block masquerading as motor neuron disease. Muscle Nerve. 1985;8:617.

9 Parry GJ, Clarke S. Multifocal acquired demyelinating neuropathy masquerading as motor neuron disease. Muscle Nerve. 1988;11(2): 103-7. 